
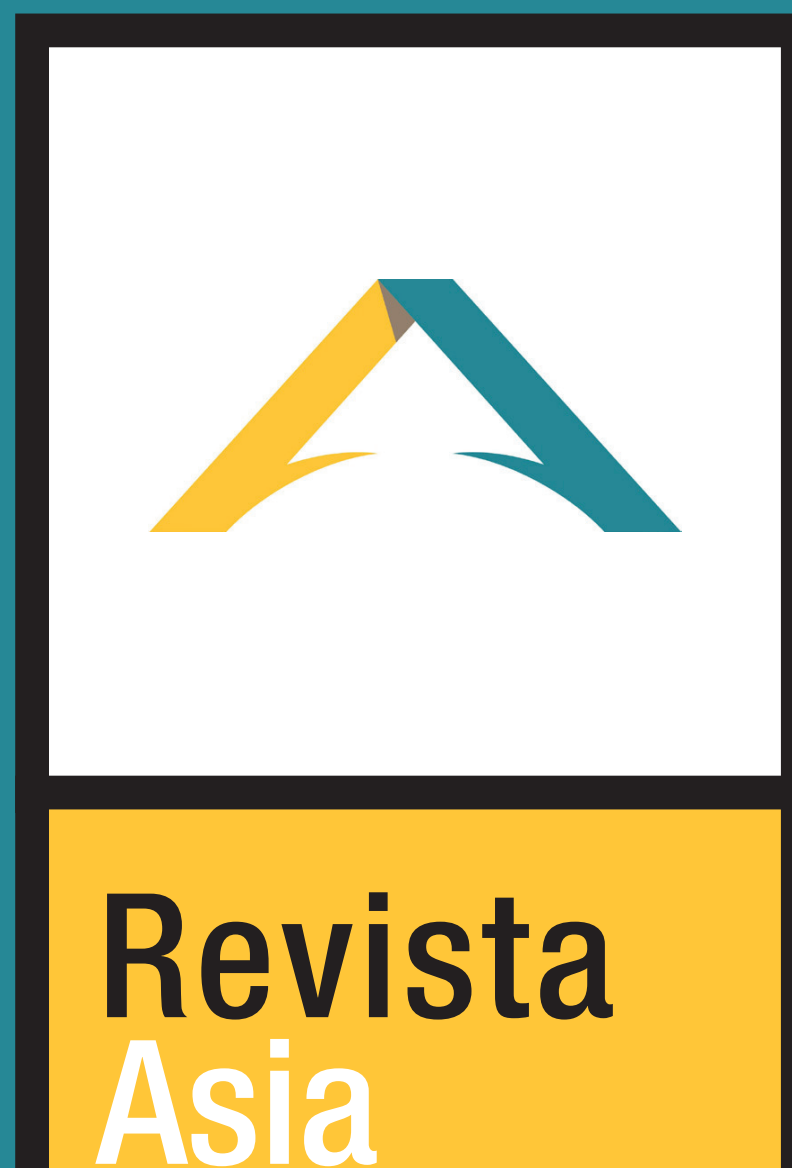

América Latina

Año 1. Volumen 1. Número 1. JUNIO 2016. Argentina ISSN 2524-9347

Grupo de Estudios de Asia y América Latina Instituto de Estudios sobre América Latina y el Caribe Universidad de Buenos Aires

\section{PRESENTACIÓN}

¿POR QUÉ UNA REVISTA SOBRE ASIA Y

AMERICA LATINA?

Fernando Pedrosa 5

\section{DOSSIER}

EL AMOR EN DOS LEYENDAS DEL SUDESTE ASIÁTICO

Mireya Sosa Abella 13

LA POLÍTICA EXTERIOR DE ARGENTINA HACIA TAILANDIA: CONDICIONAMIENTOS POLÍTICOS Y ECONÓMICOS DENTRO DE UNA ESTRATEGIA DE DIVERSIFICACIÓN
M. Florencia Rubiolo
29

INTERNACIONALIZACIÓN Y DIPLOMACIA GASTRONÓMICA EN TAILANDIA

Ezequiel Ramoneda 49

BREVE ANÁLISIS COMPARATIVO DE LA CAPOEIRA BRASILERA Y LA MÚSICA SAMARA TAILANDESA Y LAS PRÁCTICAS RITUALES COMPARTIDAS

Duncan Williams

67

\section{VARIA}

LOS DESAFÍOS POLÍTICOS EN CHINA HOY

Cristina Reigadas

87

\section{DIÁLOGOS}

¿QUÉ HACEMOS CON LOS VIEJOS? UNA SIMPLE PREGUNTA NO TIENE POR QUÉ TENER SIMPLE RESPUESTA: CHINA

Diego Bernardini 105 


\section{Dirección}

Dr. Fernando Pedrosa

(Grupo de Estudios de Asia y América Latina, Instituto de Estudios sobre América Latina y el Caribe, Universidad de Buenos Aires, Argentina)

\section{Secretaría de Redacción}

\section{Mg. Cecilia Noce}

(Grupo de Estudios de Asia y América Latina, Instituto de Estudios sobre América Latina y el Caribe, Universidad de Buenos Aires, Argentina)

\section{Dr. Ariel Sribman}

(Universidad de Girona, España)

\section{Consejo Editorial}

\section{Dra. Mercedes Botto}

(FLACSO-Argentina)

Dra. María José Bruña

(Universidad de Salamanca, España)

Dra. Pasuree Luesakul

(Directora del Centro de Estudios Latinoamericanos, Universidad de Chulalongkorn, Tailandia).

\section{Lic. Patricia Piccolini}

(Directora Carrera de Edición, Facultad de Filosofía y Letras, Universidad de Buenos Aires, Argentina).

\section{Lic. Ezequiel Ramoneda}

(Centro de Estudios del Sudeste asiático. Instituto de Relaciones Internacionales Universidad Nacional de La Plata, Argentina).

Dra. Cristina Reigadas

(Instituto Gino Germani, Facultad de Ciencias Sociales, Universidad de Buenos Aires, Argentina)

Dra. Florencia Rubiolo

(Universidad Nacional de Córdoba, Argentina)

Dra. Mireya Sosa Abella

(Universidad de Malasia)

Dr. Jaime Moreno Tejada

(Universidad de Chulalongkorn, Tailandia)

Dr. Ignacio Tredici

(ex Jefe del Equipo Jurídico de la Oficina del Co-Juez de Instrucción Internacional del Tribunal Khmer Rojo, United Nations Mission of Assistance to the Khmer Rouge Trials, Extraordinary Chambers in the Courts of Cambodia)

Dr. Wasana Wongsurabat

(Universidad de Chulalongkorn, Tailandia)

\section{Eudeba}

Universidad de Buenos Aires

$1^{\circ}$ edición: junio 2016

(C) 2016

Editorial Universitaria de Buenos Aires

Sociedad de Economía Mixta

Av. Rivadavia 1571/73 (1033) Ciudad de Buenos Aires

Tel: 4383-8025 / Fax: 4383-2202

www.eudeba.com.ar

DG: Alessandrini \& Salzman para Eudeba.

Impreso en Argentina

Hecho el depósito que establece la ley 11.723

No se permite la reproducción total o parcial de este libro, ni su almacenamiento en un sistema informático, ni su transmisión en cualquier forma o por cualquier medio, electrónico, mecánico, fotocopia u otros métodos, sin el permiso previo del editor. 


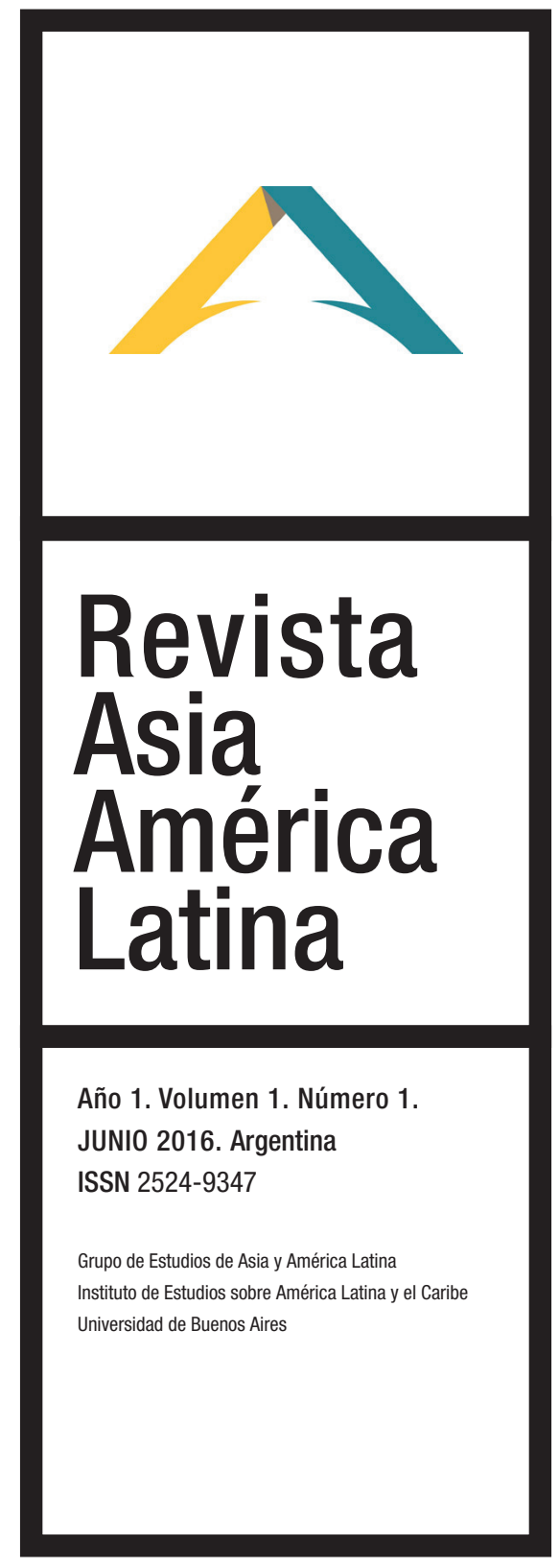

\section{PRESENTACIÓN}

¿POR QUÉ UNA REVISTA SOBRE ASIA Y AMERICA

LATINA?

Fernando Pedrosa 5

\section{DOSSIER}

EL AMOR EN DOS LEYENDAS DEL SUDESTE

ASIÁTICO

Mireya Sosa Abella 13

LA POLÍTICA EXTERIOR DE ARGENTINA HACIA TAILANDIA: CONDICIONAMIENTOS POLÍTICOS Y ECONÓMICOS DENTRO DE UNA ESTRATEGIA DE DIVERSIFICACIÓN

M. Florencia Rubiolo 29

INTERNACIONALIZACIÓN Y DIPLOMACIA GASTRONÓMICA EN TAILANDIA

Ezequiel Ramoneda 49

BREVE ANÁLISIS COMPARATIVO DE LA CAPOEIRA BRASILERA Y LA MÚSICA SAMARA TAILANDESA Y LAS PRÁCTICAS RITUALES COMPARTIDAS

Duncan Williams 67

\section{VARIA}

LOS DESAFÍOS POLÍTICOS EN CHINA HOY

Cristina Reigadas 87

\section{DIÁLOGOS}

¿QUÉ HACEMOS CON LOS VIEJOS? UNA SIMPLE PREGUNTA NO TIENE POR QUÉ TENER SIMPLE RESPUESTA: CHINA

Diego Bernardini 105

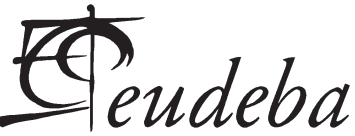





\title{
LOS DESAFÍOS POLÍTICOS EN CHINA HOY
}

\author{
POLITICAL CHALLENGES OF CHINA \\ TODAY
}

\section{Cristina Reigadas}

Universidad de Buenos Aires y Universidad de Cambridge

RESUMEN: En este trabajo se analizan algunos de los desafíos políticos de la China contemporánea; en particular, la cuestión de la democracia, a través del hilo conductor de los lemas de la ciudad de Beijing -virtud, inclusión, patriotismo, innovación-, que condensan y simbolizan la fusión entre lo valioso y aún necesario del pasado, las necesidades del presente y las expectativas del futuro. China constituye hoy un audaz experimento político que sintetiza y condensa ecléctica y pragmáticamente la ética confuciana de la virtud, la idea de democracia occidental (elecciones libres, derechos humanos, estado de derecho), el marxismo-leninismo (socialismo, justicia social) y un fuerte nacionalismo. Todo ello, al estilo chino y liderado por el Partido Comunista Chino que, más allá de su verticalismo político y de las distintas modalidades de censura que sigue ejerciendo, ha tolerado y promovido (según los líderes y las circunstancias) el debate de ideas sobre la democracia.

Pero la cuestión de la democracia china va más allá de China. Se sostiene aquí la tesis de la profunda e inevitable imbricación entre democracia china y democracia global y el rol protagónico de China en esta definición. El mayor desafío para todos los actores pasa hoy por la capacidad para los aprendizajes mutuos y la creación de novedad política.

Palabras clave: Política - democracia - China- contemporaneidad- lemas Beijingvirtud- inclusión-patriotismo -innovación- democracia global- aprendizajes mutuos - creación política.

ABSTRACT: This work analyzes some of the contemporary China's political challenges; specifically, the Democracy issue, using Beijing's slogan as a thread - virtue, inclusion, patriotism, innovation - which abridge and symbolize the fusion of the valuable and even necessary of the past, the needs of the present and the expectations of the future. In present time, China constitutes a dauntless political experiment that is summarized in an eclectic and pragmatic form, the Confucian ethics of virtue, the concept of occidental Democracy (free elections, human rights, rule of law), Marxism-Leninism (socialism, social justice) and a strong nationalism. All of this is executed in the Chinese style and is led by the Communist Party 
that, beyond it's political veritcalism and the different forms of censorship that still remains, tolerated and promoted (according to different leaders and circumstances) the debate of ideas about Democracy. But the Chinese Democracy issue goes beyond China. This article holds the thesis of profound and inevitable imbrications between Chinese Democracy and Global Democracy and the leading role of China. The biggest challenge for all players today runs by the capacity for mutual learning and creating political novelty.

Keywords: Politics - Democracy - Contemporary China- slogans including Beijingvirtue- patriotism -innovation- mutual learning- democracy globally - political creation.

\section{Introducción ${ }^{1}$}

Los cambios de escala y la aceleración de la velocidad de los cambios producidos en China, sumados a su extensión territorial, a su magnitud demográfica y a su carácter de primera potencia económica mundial, hacen que su situación política tenga un interés e impacto que excede en mucho su propio ámbito nacional. Cualquiera sea el rumbo futuro del sistema mundial y la reconfiguración de las hegemonías, China tendrá -tiene ya- un rol decisivo en la determinación de las nuevas reglas de juego en ese sistema.

No es aventurado pensar, entonces, que la construcción de la democracia en China y la construcción de un sistema democrático global marchan de la mano. Así lo han sostenido, entre otros, dos destacados intelectuales y académicos chinos. Para Wang Hui, pensar la democracia en China y pensar la sociedad mundial democrática es la misma $\operatorname{cosa}^{2}$. En la misma dirección y parecido sentido, Suisheng Zhao (2009) señala que «el progreso o la falta del mismo, en la transición de China hacia la democracia, se ha convertido en un asunto central para la comunidad internacional». Y, por cierto, para los propios chinos, quienes enfrentan el desafío mayúsculo de impulsar innovaciones políticas decisivas, que requieren asumir paradojas y despejar contradicciones.

Por un lado, la idea de democracia no es ajena a la cultura china. $\mathrm{Si}$ bien los debates sobre democracia se remontan a fines del siglo XIX y principios del XX, China ha cultivado prácticas democráticas, consultivas y deliberativas a lo largo de toda su historia. Y en la era post Mao, que haya sido Deng, numen de la Reforma y Apertura china, quien sostuviera que no hay

1. Este artículo es una versión ampliada de la comunicación presentada en la Mesa Redonda organizada por la Revista Dangdai el 20 de mayo de 2015, en la cual participaron Jorge Malena (USAL) y Mariano Tursi (Universidad Di Tella).

2. Wang Hui, El fin de la Revolución. 
modernización sin democracia (la quinta modernización es la democracia ${ }^{3}$ ) invita a revisar los prejuicios de quienes aún sostienen que la idea de democracia es ajena a la cultura política china.

Sin embargo, la cuestión de la democracia china -inclusive su mera mención- sigue levantando polvaredas dentro y fuera de China. Desde la afirmación de su inexistencia (no hay democracia en China) hasta la negación misma del problema, dado que China es democrática «al estilo chino». Fin de la historia. Estas simplificaciones suelen ser profundizadas y ampliadas recurriendo a argumentos culturales, históricos y económicos: ¿es apta la cultura política china para la democracia? ¿Es necesaria la democracia? ¿No es acaso su idea misma un producto del eurocentrismo liberal? Si bien todas estas objeciones han sido suficientemente debatidas y se han despejado los prejuicios que las sustentan, no puede decirse lo mismo de un hecho incontrastable: que la democracia en China tiene un valor instrumental y que no constituye el único valor político ${ }^{4}$.

Por el otro, la reforma política y la apertura en China se aceleran en un contexto mundial en el que conviven la «integración» económica con la desintegración social y la desigualdad, y la crisis de la democracia real con la defensa irrestricta de su principio. Por todas partes, ciudadanos desencantados y apáticos o indignados y furiosos expresan la extrema desconfianza hacia los partidos políticos y el hartazgo con un modelo político que exige con urgencia ser renovado. Así, la crisis política en Occidente se debate entre el cuestionamiento de los déficits de las democracias reales y la paradójica defensa de su principio. Pero, ¿de cuál principio democrático hablamos? La crisis de la democracia efectiva arrastra la crisis de su teoría, o mejor, de sus teorías. No se trata solo de déficits de implementación, de una mejor adecuación de teorías y doctrinas, sino de repensar cuál es la democracia necesaria para los tiempos que corren y asumir, como lo hace el pensamiento chino, que las crisis no constituyen impedimentos sino, por el contrario, oportunidades.

En este sentido, quizás no deba sorprender que «la democracia occidental no tiene mayor capacidad de corregirse a sí misma que el sistema chino» y que quizás haya más lugar para la experimentación política en China que en países con sistemas constitucionales establecidos desde hace mucho tiempo ${ }^{5}$.

3. Las otras cuatro son: agricultura, industria, defensa nacional y ciencia y tecnología.

4. Reigadas, Cristina, "La cuestión de la democracia en China. Transición democrática, gradualismo, teoría crítica y deliberación".

5. Véase Bell, Daniel A., "Democracy with chinese characteristics", en Leib, Ethan J.. and $\mathrm{He}$, Baogang, The search for deliberative democracy in China, p. 156. También Berggruen, Nicolás y Gardels, Nathan, Gobernanza inteligente para el siglo XXI, p. 42. 
Pero de ser correcta la tesis de la profunda e inevitable imbricación entre democracia china y democracia global, falta un largo camino por inventar en esta dirección y ese camino se llama capacidad para el aprendizaje mutuo y la creación de novedad. Se requiere apertura, flexibilidad y decisión de ir hasta la raíz de los problemas (¿qué otra cosa es el radicalismo político?), estar dispuesto a salir de sí mismo hacia el encuentro con el otro, a comparar, confrontar, aprender de y con otros, pensar y construir nuevos mundos. Pero si resulta difícil para los chinos flexibilizar el principio de su propia especificidad y excepcionalidad histórica, icuánto más difícil será para el egocentrismo occidental pensar que, también en este rubro, puede aprender de y con ellos!

En cualquier caso, China constituye hoy un interesante y audaz experimento político que sintetiza y condensa ecléctica y pragmáticamente la ética confuciana de la virtud, la idea de democracia occidental (elecciones libres, derechos humanos, estado de derecho), el marxismo-leninismo (socialismo, justicia social) y un fuerte nacionalismo. Todo ello, al estilo chino ${ }^{6}$ y liderado por el Partido Comunista Chino que, a pesar de o más allá de su verticalismo político y de las distintas modalidades de censura que sigue ejerciendo, ha tolerado e inclusive promovido (según los líderes y las circunstancias) el debate de ideas sobre la democracia. La existencia misma del debate y de distintas perspectivas teóricas suele sorprender a muchos académicos occidentales, dado el desconocimiento general que hay sobre los medios intelectuales chinos.

La cuestión de la «especificidad» $\mathrm{y}$ «diferencia cultural» china sigue teniendo un gran peso tanto en el imaginario popular como en el de políticos, hombres de negocios, expertos e intelectuales occidentales. En ambos imaginarios sigue vigente que, por detrás de los cambios espectaculares producidos en la sociedad china, se esconde incólume la China eterna y esencial, históricamente cerrada a Occidente. Es por ello que aún sorprende al visitante (sea o no lego) la existencia de terrenos comunes desde los cuales dialogar. El académico occidental, preso aún de la metáfisica e hijo de los «maestros de la sospecha», busca siempre más allá de lo que se le aparece y presenta, y se desilusiona cuando advierte que los académicos chinos discuten los mismos autores y teorías que ellos (además de repensar sus experiencias e historia). Ganados por las críticas al eurocentrismo y el deseo de captar la singularidad en toda su concreta plenitud, más allá de las máscaras

6. Hablar del "estilo chino" requiere actualizar el debate universalismo/relativismo. Que los chinos tengan su "estilo" no constituye excepcionalidad alguna. Lo que la constituye es el modo singular en que enlazan sus historias, experiencia y tradiciones con otras. O seguiremos creyendo, con Hegel y Fukuyama, que hay pueblos universales e históricos y otros meramente particulares y no históricos? 
ideológicas del universalismo, algunos se preguntan aún: ¿̇será éste el auténtico pensamiento chino? Y si no, ¿dónde y cómo encontrarlo? ¿Es posible que lo auténticamente chino se exprese en un idioma que no sea chino? ¿Puede hallarse el verdadero pensamiento chino en los escritos de académicos e intelectuales globalizados, formados en las «usinas» de pensamiento occidental? ¿No estaremos presos (iy ellos también!) una vez más de las astucias de la razón occidental?

Sin embargo, y más allá de estas cuestiones, el debate crece en interés práctico y calidad teórica. Así compiten liberales universalistas y comunitaristas, la nueva izquierda nacionalista (maoísta) y la teoría crítica, los partidarios de la democracia deliberativa y los neo-neoconfucianos. Pero la existencia del pluralismo teórico no debe hacernos olvidar que hay cierto consenso «centrista» que forma la mainstream de lo que China quiere y espera de la democracia: que respete su peculiar estilo de hacer política (la diferencia china) y un camino gradualista e incrementalista de realizar los cambios cuyo horizonte último es la construcción de una sociedad socialista armoniosa7 .

La perspectiva oficial, política y académica (ambos espacios van en China muchas veces -aunque no siempre- de la mano) plantea la democracia en términos de gobernanza y participación: cómo lograr la cooperación armoniosa a nivel global y a nivel nacional, cómo convivir pacíficamente con los demás Estados en pie de equidad y cómo redefinir y mejorar los vínculos entre sociedad civil y Estado, entre gobernados y gobernantes, y entre los ámbitos locales, provinciales y nacionales, habida cuenta de los profundos cambios que atraviesa la sociedad china ${ }^{8}$.

\section{Los lemas de Beijing}

Algunos de estos desafíos están sintetizados en los lemas que la ciudad de Beijing ha asumido como objetivos políticos: virtud, inclusión, nacionalismo e innovación. Estas palabras clave condensan y simbolizan la fusión entre lo valioso y aún necesario del pasado, las necesidades del presente y las expectativas del futuro. De fuerte presencia en los espacios públicos de la ciudad, constituyen un ejemplo significativo de lo que se reconoce como

7. Yu Keping, «Democracy is a good thing».

8. Hay que señalar que los políticos chinos prefieren hablar de participación popular y no de democracia, aunque en los debates académico-políticos no se rehuye el término. A su vez, «gobernabilidad» constituye un claro préstamos de la teoría política occidental que el establishment político e intelectual chino asume sin complejos ni prejuicios. Otro préstamo significativo es el de «sociedad civil», aún cuando se lo asume como controversial. 
la idiosincrática relación china entre continuidad y discontinuidad histórica, entre lo que los occidentales llamamos «tradición» y los conceptos compartidos, aunque diferenciados, de «modernidad». Y, como siempre para los chinos, se trata de metas que se concretan mediante la realización de los planes gubernamentales y cuya mirada está puesta en el largo plazo.

\section{II.1. Virtud}

¿A qué virtudes apelan los chinos cuando la política necesita de alguna? ¿Y por qué esta apelación constituye un desafío?

En primer lugar, se trata de las virtudes confucianas, acerca de las cuales mucho se ha escrito en los últimos tiempos, en particular acerca de su relación con la democracia. Sin ser democrático ni antidemocrático (el confucianismo no es una doctrina política sino una ética), sus valores (la virtud, el respeto, la devoción filial, el cuidado, la austeridad, el orden, el mérito, la cooperación y la armonía, entre otros) pueden contribuir notablemente a fortalecer la democracia. Tal es el revival confuciano que, lejos de limitarse al espacio geopolítico y geocultural chino, ha trascendido fronteras. De modo que las nuevas versiones del neoconfucianismo se postulan como el nuevo paradigma ético apto no sólo para refundar la política en China sino para la reconstrucción democrática de la sociedad global, como lo plantea, por ejemplo, el neoneoconfucianismo de Boston, liderado por el filósofo Tu Weiming. Y tal como es defendido militantemente por el filósofo norteamericano, residente en Beijing, Daniel A. Bell, uno de los más entusiastas exponentes de la democracia de cuño neoconfuciano.

En segundo lugar, este revival constituye un intento de relegitimar al Estado y paliar los efectos de la economía de mercado, del materialismo consumista y de su consecuente exitismo e individualismo, por un lado, y del aumento de la corrupción, por el otro. Hoy ya no hay épica revolucionaria ni controles férreos que legitimen al régimen, y el bienestar de hoy y para algunos puede trocarse en el malestar de mañana y para otros.

Frente a esta precariedad legitimatoria y a la creciente contradicción entre los valores de una economía de mercado (capitalista) y una política socialista (de partido único), el gobierno ha optado por la fuerza persuasiva de la ética confuciana.

Pero, se sabe, revivir tradiciones éticas no es sencillo. Y mucho menos conocer el alcance de este revival en China, dada la carencia de datos e investigaciones sobre la cuestión de las creencias. ¿Es el confucianismo una ética adormecida, que puede recobrarse mediante operaciones de política cultural, o pertenece definitivamente al pasado? ¿O, como creen muchos, está aún vigente en la cultura popular? 
Cualquiera sea el caso, hay una política oficial de apelación a la ética de la virtud, hay movimientos intelectuales que procuran discutir los modos de incorporar estos valores en las instituciones políticas y sociales chinas y hay prácticas sociales confucianas. En este sentido, el confucianismo no es sólo una cuestión de las élites. La sociedad se ha adueñado rápidamente de estos requerimientos y ha creado escuelas confucianas, en donde se valora la repetición y la memoria, mezclando a Confucio con las neurociencias, y celebra encuentros multitudinarios de estilo mediático, verdaderos shows en donde se canta y baila en nombre de Confucio, aunque se lo nombre poco y se sepa de él aún menos, pero que funciona como una marca que cobija a todos los asistentes por igual ${ }^{9}$.

En todos los casos, provenga de las propuestas gubernamentales, de las élites intelectuales o del popconfucianismo, la cuestión central es cómo se redefine la relación entre tradición y modernidad, términos ya definitivamente enredados y de fronteras borrosas. Por otra parte, la opción gubernamental por el confucianismo no debe hacernos olvidar que éste no es la única tradición ética china, aunque haya sido (¿sigue siéndolo?) hegemónica, y que en China comienzan a adquirir creciente visibilidad diversas prácticas religiosas populares, cultos animistas y sincréticos que han sido cuidadosamente ocultados y/o silenciados y cuyo renacer produce sorprendentes interacciones sociales entre los miembros de la comunidad y sus líderes religiosos y políticos ${ }^{10}$.

No es nueva, por otra parte, esta necesidad de reinventar la (una) tradición. Ya en la época de Mao los valores confucianos fueron objeto de bajas y subas al calor de las vicisitudes políticas. Pero las tradiciones se reinventan cuando se han perdido y su reinvención no puede conseguirse por decreto. He aquí el desafío político que plantea el legado confuciano.

\section{II.2. Inclusión}

El segundo desafío a la política proviene de la economía. El concepto de inclusión deviene particularmente apto para cobijar la multivariedad de problemas originados en su demanda, a la vez que honra el legado marxista de participación social igualitaria y justicia social. Para el régimen, no basta

9. Esto bien puede verse como parte del desembarco posmoderno en China, que se profundizará, seguramente, con el creciente consumismo, apertura y espíritu de independencia y que es llamado "confucianismo de estadio». Véase Billioud, Sebastien and Joel Thoraval (2014), The Sage and the People, The Confucian revival in China, Oxford University Press.

10. Adam Yuet Chau (2006), Miraculous Response: Doing Popular Religion in Contemporary China, Stanford University Press. 
con asegurar la subsistencia: ésta debe ir de la mano de un desarrollo armonioso, que constituye el derecho fundamental para los chinos y que reemplaza, en su interpretación, la noción individualista de los derechos humanos occidentales. Contra el desarrollo armonioso atenta, sin duda, la creciente desigualdad de ingresos, tanto a nivel individual como regional, dos de los problemas más importantes que China enfrenta en la actualidad. Al revés de lo sostenido por las teorías liberales del crecimiento económico (primero crecer, luego repartir), el Partido Comunista Chino ha sostenido que sin participación en la distribución de los bienes materiales, simbólicos e institucionales no hay verdadero desarrollo.

A la inclusión económica hay que agregar la inclusión social y política. $\mathrm{Al}$ respecto, la situación de los migrantes internos es acuciante. Hacinados en guetos, marginados de la vida de las ciudades en las que trabajan, lejos de sus familias y de su cultura, en su mayoría rural, carentes de derechos, los migrantes han sido y siguen siendo ciudadanos de segunda, destinados a deambular de ciudad en ciudad y a aceptar las injustas reglas de residencia.

Integrar y promover el desarrollo de las regiones atrasadas mediante iguales oportunidades económicas, laborales, educativas y de salud; equilibrar las pretensiones autonómicas de los diversos grupos étnicos y los intereses del Estado nacional, sin apelar a la violencia política e institucional; garantizar el pluralismo cuando de diversidad étnica y religiosa se trata; mejorar la situación de las mujeres y el creciente abandono de los ancianos (que ha llevado al gobierno a promulgar una ley que obliga a los hijos a visitar por lo menos dos veces al año a sus padres); detener la disminución de la fuerza laboral (que ha llevado a revisar las políticas del hijo único y a la promulgación de nuevas leyes al respecto); cumplir con las políticas de cuidado del medio ambiente y, a la vez, sostener el ritmo de desarrollo humano requerido para garantizar el bienestar son otros tantos desafíos de las políticas de inclusión.

A todos éstos, el gobierno chino responde de un modo u otro: si hay algo que lo caracteriza es el hacerse cargo de sus problemas. Así, la cuestión de los derechos de los migrantes es hoy una prioridad de la política social a nivel nacional tanto como la necesidad de disminuir la brecha entre regiones. Las cuestiones ligadas a las pretensiones autonómicas y a los grupos religiosos disidentes son de más difícil solución, habida cuenta del indeclinable sentido de la soberanía territorial chino y del miedo a que las voces disidentes desestabilicen el régimen.

Otra cuestión central en términos de inclusión, desarrollo armonioso y gobernabilidad es el empoderamiento de la sociedad civil a través del incremento y autonomía de las asociaciones comunitarias que cooperan con el Estado en la prestación de servicios sociales. Este tema es clave en la 
definición de un nuevo modelo de gobernanza y ocupa el interés de políticos $\mathrm{y}$ académicos por igual.

Si bien se observa un incremento de organizaciones y de reglamentaciones para su organización, éstas siguen funcionando como asociaciones cuasi estatales, cuyo margen de autonomía varía según su interés estratégico y las tareas que desempeñan. En su gran mayoría, el Estado terciariza en ellas la ejecución de políticas sociales estatales, a veces a propuesta de las mismas asociaciones, otras a través de las oficinas gubernamentales, pero en todos los casos, el estado controla tanto la formulación de objetivos y definición de tareas en función de los planes gubernamentales como la ejecución y supervisión de las mismas. De todos modos, hay consenso acerca de la necesidad de fomentar una sociedad civil más autónoma y plural, con menos obstáculos burocráticos y menos controles y censura.

La cuestión del pluralismo ideológico y de la libre expresión de las ideas, ya sea en medios escritos periodísticos y muy especialmente en las redes sociales constituye un terreno conflictivo, en el cual China no ha realizado grandes progresos. Por el contrario, la ley de seguridad promulgada recientemente por Xi Jinping parecería reforzar los controles ideológicos y la censura a la libertad de expresión.

En cuanto a la participación política, la cuestión del voto libre y universal y el multipartidismo no forman parte, por el momento, de la agenda política. Y esto por múltiples razones, siendo las de mayor peso: que el sistema funciona bien, que los chinos están felices con él (un 70\% según las encuestas) y que la introducción de semejantes cambios podría desestabilizar al régimen.

Por cierto que el voto y el pluralismo son cuestiones centrales en cualquier democracia pero también es cierto que no hay un único modo de entender y/o practicar ambos, ni siquiera en Occidente. Las contradicciones irresueltas de la democracia occidental suelen ser un ejemplo muy utilizado por los chinos para justificar la democracia «al estilo chino».

Por otra parte, los chinos confían en que el gobierno sabe lo que el pueblo necesita y que, en caso de error, es capaz de rectificar el rumbo. $\mathrm{Y}$ el gobierno «sabe» lo que el pueblo necesita porque cuenta con dos herramientas básicas que contribuyen a la gobernabilidad: la planificación basada en el conocimiento experto y las encuestas mediante las cuales se efectúan sondeos permanentes de la opinión pública, en relación a los niveles de satisfacción con las acciones de gobierno. En este modelo político no hay aquí mesianismo alguno, sino expertise y pragmatismo. A diferencia de Occidente, este modelo se construye de «arriba hacia abajo» y se funda (confucianismo mediante) en la devoción filial a la autoridad que sintetiza la experiencia de los tiempos y el conocimiento de los sabios. 
En este sentido, el punto de partida de la relación política en China es la confianza que los gobernados depositan en los gobernantes y que, sin duda, tiene su origen en la configuración imperial coronada por el rey-padre. A diferencia de Occidente, donde el sistema político democrático (de abajo hacia arriba) se construye a partir de la desconfianza que generan las autoridades, siempre sospechadas de cercenar libertades y derechos. Es por ello que el gobierno chino ha declarado una guerra sin cuartel a la corrupción (al menos discursivamente), ya que su expansión corroe el principio mismo de confianza en su autoridad. Y es por ello que apela a la ética de Confucio.

Sin embargo, la sociedad china cambia aceleradamente y parecería asumir cada vez más modelos y estilos occidentales de vida. Por ello, es difícil saber cuánta reserva ética confuciana tiene la sociedad china y, en el caso de existir, cómo podría legitimar a un sistema político atrapado entre los imperativos del mercado y el siempre vigente compromiso con el socialismo.

Que la mayoría del pueblo chino esté conforme con sus autoridades no significa que no reclame y demande a las mismas mayor bienestar y derechos. O que los debates sobre diversas formas de participación popular y de democracia estén ausentes.

En particular, llama la atención el creciente interés que manifiestan destacados intelectuales chinos por el giro deliberativo de la democracia contemporánea. Así lo demostró el entusiasmo que suscitó la visita de Habermas en los años 1980, cuyo pensamiento actuó como «catalizador» de los nuevos tiempos. Muchos de los temas centrales habermasianos (acción comunicativa, construcción racional consensuada de la voluntad política y de la opinión pública) coinciden con aspectos de la cultura política china, tradicionalmente orientada a la búsqueda de consensos (armonía) y amante del diálogo y la deliberación (entre las élites). Estas apreciaciones históricas, unidas a las crecientes prácticas deliberativas, en especial a nivel local, han llevado a Ethan Leib y Baogang He a sostener que hoy China puede estar más abierta a innovaciones democráticas que muchas democracias occidentales.

Los procesos de deliberación no necesitan empezar con las elecciones y pueden legítimamente evolucionar mediante formas participativas de gobernanza democrática. El aumento de audiencias públicas, consultas, foros, encuestas grupales se ha incrementado notablemente en los últimos años.

Aun cuando, por el momento, reconoce Baogang He, estas deliberaciones tienen un sesgo autoritario que deberá ser reemplazado en el futuro por un diseño democrático institucional basado en la normatividad del derecho.

Sin embargo, la deliberación no puede sustituir la necesidad de democracia intrapartidaria a través del voto. Para Yu Keping, intelectual estrella del firmamento político chino, asesor de $\mathrm{Hu}$ Hintao y famoso por una entrevista que dio en 2005, publicada luego en un artículo titulado «La democracia es una cosa buena», sostiene que sin democracia intrapartidaria no 
hay democracia posible en China ni posibilidad de permanencia del régimen político. Se trata, lisa y llanamente, de una cuestión de Estado. Este proceso de ofrecer más personas que asientos en las elecciones de miembros del Congreso del PCCH y en otros cuerpos electivos locales, provinciales y nacionales está en marcha y se ha incrementado el porcentaje de miembros electos de forma directa, aspirándose a eliminar la restricción de ser miembro del partido para la elección de los cargos locales.

Yu apoya también las elecciones populares de base, que ya existen en más de la mitad de los municipios chinos y en un $70 \%$ de las localidades rurales. También sostiene la necesidad de reformas administrativas, a fin de eliminar la superposición y multiplicación de instancias administrativas locales y centrales que incrementan el despilfarro de recursos, la corrupción y la ineficiencia, a la vez que ponen en evidencia los límites del tan mentado centralismo político chino.

Para Yu, el proceso de construcción de la democracia debe ser gradual. La democracia es buena porque proporciona seguridad y armonía y se la teme porque los políticos pueden perder sus privilegios, pero es necesaria como legitimación política, dado que provee más estabilidad en el largo plazo. Pero su realización debe ser incremental y sus costos, calculados.

En este camino, la institucionalización de la ley es clave. Como ha sostenido el actual presidente, Xi Xinping, si bien China no es aún un Estado de Derecho, debe asumir la tarea de convertirse en un Estado con Derecho. En este tránsito, cabe preguntarnos si las nuevas legislaciones contribuirán a reforzar la autoridad del poder estatal frente a los reclamos por una mayor inclusión e igualdad o estarán orientados a institucionalizar los derechos de los ciudadanos. Por lo que se ve, las nuevas leyes promulgadas parecen ir en la primera dirección, buscando un mayor control gubernamental de la opinión pública y de los derechos de las minorías.

La inclusión, entonces, busca fundarse en la síntesis de diversas tradiciones: los ideales comunitaristas y deliberativos de la tradición china, las ideas de justicia social del marxismo-leninismo y los principios de la democracia liberal de Occidente, todas ellas convenientemente aggiornadas.

\section{II.3. Patriotismo}

El tercer desafío que plantea la política china es el patriotismo, de fuerte sesgo nacionalista. ¿Porqué constituye un desafío político? Porque el nacionalismo y la defensa de la soberanía se erigen en valores incuestionables para China en medio de un escenario fuertemente globalizado, en el cual los Estados nacionales han fracasado en el control de la economía debido, justamente, a la persistencia de modelos estatales obsoletos. ¿Cómo se conjugará 
el nacionalismo chino con su misma propuesta de construcción de una sociedad mundial basada en la cooperación armoniosa? ¿Podrá China gozar y defender la democracia en las instituciones globales (un país, un voto) sin practicarla internamente? ¿Podrá constituirse China en una superpotencia que deje atrás las rémoras de la política internacional del siglo XX y contribuir a forjar nuevas reglas de juego globales sin despojarse de su extremo nacionalismo? ¿Podrá ir China más allá del neocolonialismo en sus relaciones sur-sur o instaurará en ellas nuevos vínculos de dependencia? ¿Cómo conjugar la cuestión del «estilo chino», de que China no dejará de afirmar su «diferencia» con los requerimientos de la democracia global? Y, fundamentalmente, ¿cómo se avanzará en la interpretación y aplicación de los derechos humanos?

\section{II.4. Innovación}

Renovar la virtud confuciana, promover la inclusión de cientos de millones de personas, reforzar el patriotismo en las condiciones del sistema global requieren capacidad de innovar.

Ciertamente, los desafíos que enfrenta China son similares a los que enfrentan muchos otros países, pero la diferencia estriba en la cualidad de las cantidades y magnitudes y en la vertiginosidad de los cambios en un contexto de crisis mundial, quizás civilizatoria. $Y$ en la circunstancia de estar abocada a un acelerado proceso de industrialización al mismo tiempo que emerge como primera potencia mundial.

Proponerse realizar el socialismo mediante instrumentos de mercado capitalista constituye, sin duda, un extraordinario experimento político. Tanto como morigerar los desastres producidos por el modelo de desarrollo asumido, en particular en relación al medio ambiente. En este campo, China oscila entre las necesidades de inclusión y la imperiosa redefinición del desarrollo en términos de sustentabilidad ecológica.

Finalmente, China necesita nuevas formas de revitalización de la confianza en el gobierno, socavada por la corrupción gubernamental, y buscar nuevas formas de legitimación más allá del bienestar económico que produce el crecimiento del consumo. Tanto el aumento de la corrupción como una eventual crisis económica pondrían en aprietos a un régimen político vertebrado en torno a un partido único y aún sin los suficientes contrapesos institucionales.

Por cierto, la innovación no consiste para los chinos en empezar de nuevo ni tampoco en aferrarse al pasado o al presente, sino en pensar el futuro desde la mezcla y síntesis de experiencias y tradiciones pasadas y presentes, propias y ajenas. En este sentido, hay que destacar el extremo pragmatismo 
chino, que va de la mano de un importante sentimiento de autoafirmación, que le permite escoger libremente en función de sus intereses y no de prescripciones ideológicas, políticas o éticas abstractas.

Que la innovación está ligada a la idea de desarrollo científico no constituye tampoco ninguna novedad ni es una idea importada de Occidente. Pero sí debe hacerse cargo de dos de los problemas más importantes de China: superar las rémoras de una educación esquemática, repetitiva, y memorística, a fin de garantizar la apertura de la población china -no sólo de sus élites- al mundo y evitar que el precio del extraordinario crecimiento económico sea la contaminación y degradación ambiental y el uso abusivo de los recursos naturales, que conduzca a un nuevo «gran salto» de consecuencias impredecibles.

\section{Recapitulación y síntesis}

1) Sostener la inexistencia de democracia en China constituye un prejuicio eurocéntrico, fundado en la creencia de que hay un único modelo de democracia (el occidental liberal).

2) La cultura política china es apta para la democracia, aun cuando el nacionalismo y el materialismo -y no la democracia- sean los valores políticos centrales.

3) El abordaje pragmático y utilitario de la democracia como fuente de legitimación y garante de estabilidad del régimen político comienza a complementarse con una apreciación del valor de la democracia como un bien en sí mismo.

4) La democracia es un tema ampliamente debatido por políticos y académicos chinos, aun cuando hay visiones diferentes y rivales de la misma. Dicho debate no es pro ni antioccidental, sino que pragmáticamente busca y utiliza recursos de distintas tradiciones políticas, propias y ajenas, en función de dar solución a los problemas y necesidades chinas.

5) El camino a la democracia «a la china» es y debe ser gradual y está conformado por aportes y adaptaciones de la democracia liberal, de la democracia participativa y deliberativa, del socialismo marxista y de la propia tradición china, en particular, del nuevo confucianismo.

De todos ellos toma y reelabora distintos aspectos y dimensiones:

a) las elecciones, b) el Estado de Derecho, c) los controles y contrapesos institucionales, d) la defensa de los derechos de la humanidad, e) la promoción del pluralismo, f) una creciente autonomía de 
la sociedad civil, g) la inclusión con justicia social e igualdad, h) la deliberación de la ciudadanía, i) la ética vinculada a la política, el concepto de gobernante ejemplar y ciudadano virtuoso, j) el sentido de lo colectivo y del bien común, k) la meritocracia basada en el respeto al sabio y a su conocimiento.

Todos estos componentes de la democracia convergen en la idea de armonía y se procuran mediante un fuerte intervencionismo estatal, cuyas claves políticas son el nacionalismo, la defensa de la soberanía territorial y el crecimiento económico.

Estas asunciones exhiben, sin embargo, importantes diferencias de interpretación respecto del «modelo» occidental liberal, así como restricciones prácticas.

Respecto de: a) para los chinos la democracia no se agota ni radica exclusivamente en las elecciones, aun cuando la realización de elecciones directas locales es considerado el mayor logro político de la últimas décadas; b) se avanza hacia un Estado con Derecho, aun cuando no en lo inmediato, de Derecho; c) el Estado chino es fuertemente intervencionista y no cede su rol controlador, aun cuando desde el gobierno se busca eliminar la superposición de tareas administrativas que dificultan la gestión y redoblan controles innecesarios como así también fomentar la participación ciudadana mediante prácticas y experiencias de democracia deliberativa, a fin de intensificar el poder ciudadano y contribuir a la descentralización y el federalismo; d) en cuestión de derechos humanos se sustenta también una perspectiva diferenciada «a la china», fundada en la concepción colectiva de los mismos, y comienzan a cobrar importancia los derechos de algunos grupos como los de los migrantes internos; e) hay una mayor apertura y tolerancia a las diferencias de opinión y a su libre expresión, aunque permanece la censura; f) se multiplican las organizaciones de la sociedad civil, que comienzan paulatinamente a independizarse del Estado en lo que hace a su creación, planificación, organización y gestión; g) los logros notables en el terreno de la inclusión no han conseguido, sin embargo, reducir la desigualdad; h) aumentan las experiencias y prácticas deliberativas; i) la corrupción política y económica es uno de los mayores desafíos que enfrenta el Estado y el $\mathrm{PCCH}$, y el éxito del actual modelo político-económico depende de su capacidad, si no para erradicarla, para por lo menos limitarla; j) mantener el sentido de lo colectivo y de la solidaridad, a la vez que posibilitar el desarrollo de los intereses y preferencias individuales, en el marco de una 
sociedad fuertemente estatalista con una economía que promueve el consumo y celebra la riqueza; $\mathrm{k}$ ) preservar la meritocracia en la conducción política y en la estructura y organización social, sin ceder a las presiones de las nuevas élites basadas en el poder y la riqueza, y promover la igualdad de oportunidades educativas sin caer en el populismo pedagógico.

6) Hay consenso en la necesidad de democratizar el partido, aun cuando no respecto a la introducción del multipartidismo.

7) Hay preferencia por formas democráticas participativas y prácticas deliberativas mientras no atenten contra el monopolio político del partido único.

8) La construcción de la democracia en China y de la democracia global están asociadas y en ambos ámbitos la gobernanza constituye una cuestión clave.

\section{Bibliografía}

BeLL, Daniel A. (2006). "Democracy with chinese characteristics", en Leib, Ethan $\mathrm{J}$. and He, Baogang, The search for deliberative democracy in China. Nueva York: Palgrave-Macmillan: pp. 149-161.

BERGgRUEn, N. y GARDELS, N. (2013). Gobernanza inteligente para el siglo XXI. Buenos Aires, Taurus.

CAO, W. (2006). "The historical effect of Habermas in the Chinese context: a case study of the structural transformation of the public sphere", en Frontiers of Philosophy in China, vol. 1: 41-50.

Leis, E. y HE, B. (2006). The search for deliberative democracy in China, Nueva York, Palgrave-Macmillan.

Reigadas, C. (2014). "La cuestión de la democracia en China. Transición democrática, gradualismo, teoría crítica y deliberación”, en Michelini, D. (dir.), Revista de la Red Latinoamericana de Etica del Discurso, Fundación ICALA, disponible en: http://www.icala.org.ar/RED/eticadiscursiva.html.

Sen, A. (2005). La démocratie des autres. Paris, Payot y Rivages.

Suisheng, Z. (ed.) (2000). China and Democracy. Reconsidering the Prospects for a Democratic China. Londres-Nueva York, Routledge.

WANG HUI (2009). The End of Revolution, China and the Limits of Modernity. Londres-Nueva York, Verso.

Yu KePIng (2009). Democracy is a good thing, Essays on Politics, Society and Culture in Contemporary China. Washington, Brookings Institution Press. 

